\title{
VISUAL ARTS IN EGYPT, BETWEEN RE-READING HISTORY AND THE INFLUENCES OF WESTERN CULTURE
}

Walid Muhammad Abdullah QANOUSH *

Painting Department, Faculty of Fine Arts, Alexandria University, Egypt

\begin{abstract}
The fields of artistic creativity are distinguished from other areas of life by that ability to express the state of civilized, knowledge, social and also economic societies, and it is historically proven that there is no single example indicating that a society has witnessed its arts sophistication and distinction and its creative products achieved a special personality and made a strong impact in periods The collapse and decline, and it is also proven that all the major transformations in the art movement and its concepts were mainly related to the general societal achievement, in the ancient Egyptian civilization the flourishing arts were associated with periods of political stability and prosperity, and in Islamic history the arts of architecture, applied arts and other arts fields flourished during periods of expansion and scientific and economic progress. In Europe, the art movement and its development accompanied the stages of growth and development beginning with the Renaissance.

Keywords

Visual Arts, Egypt, History, Western Culture.
\end{abstract}

\section{Introduction:}

The shape and nature of the arts in general changes to meet the needs and reflect the aspects imposed by the emerging, existing or stable state of development to suit that state, its motives, and the needs and interests of society.

Usually every emerging civilization searches for a starting point to start a new journey in the paths of creativity, and the most famous launch pad, as history has shown us, is the path of returning to the bright spots in the achievements of the former, or what we used to call the inspiration of heritage, while trying to re-read it in a manner that suits the new stage.

However, a meditator in the history of art simply discovers that no emerging civilization has relied on its inspiration from heritage on methods and methods of creativity from other civilizations, in an attempt to marry contemporary and rooted identity

Hoped. Since the era of Muhammad Ali Pasha and his successors and over the course of more than two hundred years, there has been talk about the renaissance of modern Egypt, without a real project for the renaissance that relies on clear foundations and milestones related to the nature of the earth, people and belief, and without sufficient awareness of the general data that enable or disrupt any real project for the renaissance.

This is what made all the continuous modernization attempts in the fields of creativity based on two basic sources and the attempt to mix between them: the past represented in the artistic

*Corresponding author: finea-dean@alexu.edu.eg 
heritage of past civilizations and the present represented in the artistic methods, means and techniques prevailing in other cultures, and the essence could have changed if its appearance changed.

The researcher believes that this point was and still is the basic problem that the Egyptian art movement suffers from throughout its short history, which is the claim of modernity, then the claim of contemporary, and at the same time the conviction of privacy and individuality. This research tries to point to that problem to clarify the difference between the concept of inspiring the past and re-reading history, and between exploiting the available means, techniques and methods, and at the same time reaching a unique personality that necessarily expresses the state of society with everything in it.

I would like to start this study by emphasizing a fact that is almost historically fixed, and some scholars and specialists may think that it does not need clarification or proof, which is that the doctrine, with its philosophical characteristics, ideas, assumptions and ways of life, has governed throughout history, not only in the subjects of artistic works But also in its apparent and formal forms, and based on the data of their beliefs, the artists were able to create forms and visual media through which (and only through) they could respond almost literally to the requirements imposed by the ideological development and the philosophical and intellectual development that followed upon the accompanying civilization.

In the past, creed was the main supportive engine for the emergence of every stable and continuous civilization, as happened in Egypt, Iraq, China, Greece and Latin America. To set a general order for society, and in which all also responded to the general cultural and artistic product in particular, direct responses that were able to translate all ideological manifestations to serve the political and social goals set by the political systems of a civilization.

In spite of the similarity of the basic foundations necessary for the emergence of a civilization, such as the geographical nature and the environment, or even the system of government in its general concept (the rule of the individual), the decisive element in distinguishing between the artistic product was undoubtedly the belief adopted by a society that said a belief that formed the ancient forms of art. Rather, it has defined its fields and methods of implementing it in a way that is inevitable and cannot be discussed.

And every prosperous civilization was able to impose on other weaker civilized societies in its periods of decline, its doctrinal and social values, and thus its artistic methods. This was clearly evident in Egypt and the countries of the Middle East, where the nature of the artistic product in Egypt changed - for example - to become a mixture between the two faiths with what they present in terms of forms and mediums. Expression. Likewise, what happened when 
Christianity appeared in Egypt and at the emergence of the Islamic state, and its military and ideological control over areas of lands and societies in most countries of the East and North Africa and overtaken by some regions of southern Europe.

That effect differed according to the nature of each civilized region conquered by the Muslims, while the effect was decisive in creating new vocabulary and methods or developing existing ones, as happened in Egypt, the Levant and some North African countries, it was partly in other regions whose existing arts were able to absorb the data presented by the Islamic faith. Thus, a different mixture was produced that carried the essence of Islamic thought and some of the original manifestations of art, as happened in Persia and some regions of China and Anatolia. Partly escaped from this the Far Eastern countries that were not reached by the Romans or Muslims, so they preserved two things, the first is its beliefs and philosophies, and the second its distinctive artistic characteristics, and the ancient Latin American civilizations escaped entirely, so their art remained pure and somewhat extended.

And with the disintegration of the Islamic state at a time when the Church dominated the conflict-ridden European society until the outskirts of the fifteenth century, leading to the societal conflict in Europe, which ended with the predominance of scientific thought, the approach based on research and study, over religious ideas that caused and strengthened ideological and sectarian conflicts. Political ambitions over the course of the dark centuries in Europe, and with all that arose the Western civilization project known as the European Renaissance, bypassing for the first time in history the theses of religion and relying on a new belief based on science, respect for the role of the individual in society, and the elevation of his humanity, and this transformation did not occur in isolation from religious authority, Up to the French Revolution at the end of the seventeenth century, which ushered in the final elimination of religious authoritarianism and its control over European culture, which was the precursor to the emergence of a new faith

Western thought has prevailed to this day, which is to uphold the values of individualism and humanity, get rid of the restrictions of narrow religious conflicts, and allow the creative mind to take its way in producing ideas, which resulted in what was called the second wave civilization or the industrial revolution, which opened the door wide to the development of arts in a form. General, depending on what the emerging civilization project at the time presented in semi-direct responses to the emerging intellectual data, and with a remarkable amount of change in the formal forms of the visual arts corresponding to every new proposal presented by societal development. 
All this at a time when Egypt lost its central position as a cultural outpost of intellectual sovereignty and privacy after its fall in the hands of the Greeks, then the Romans, and then with the Islamic conquest of the successive political stages that ended with its subordination to the Ottoman Caliphate and then its fall under the English occupation, a period of time that lasted more than For the two thousand years, during which the pure Egyptian civilization project ceased to exist, and during which Egypt lost its original relationship with art, except for the manifestations of Coptic art produced by the Christian faith and in which Egypt participated in the production of Islamic arts as part of a large cultural, political, and ideological project.

And to this day, and despite successive attempts, the Egyptian community has not been able to present its own civilization project, due to many circumstances and reasons. This is not the area of its presentation, which is clearly reflected in the nature of the artistic product in the phenomenon of the year.

At a time when the West and many countries in the East, such as Japan and finally China, were able to transcend the idea of religion as an intellectual doctrine and a ruling framework for society, to philosophies and civic ideas based on promoting the values of civilization and national belonging, and general openness to all new ideas This is what puts the idea of identity in its traditional sense on the line, and it immediately comes to mind; Many questions about the meaning of the word.

And the researcher clearly sees that there is no contradiction or contradiction between the idea of (local) identity and the concept of contemporary, with the most important conditions being that we initially agree on the concept of identity and its definition, and also what do we mean by contemporary? And, following simple academic methods, identity is defined in language as a term of the pronoun that is, and its meaning is the characteristics and truth of a person, and it is also used to refer to the features and characteristics that characterize the personality as well as as the totality of the features that distinguish something from another, or a person from another. Or a group from others, so the personal identity defines a person in his form, name, characteristics, age and nationality, while the combined identity (national or national) denotes basic common features of the group of people that distinguish them from other groups, and thus the cultural identity is the total of the technical characteristics and features And social, customs, traditions, beliefs, and practices characteristic of the society alone.

As for contemporary, it is a word derived from the word era, meaning the age or time, and accordingly it can be interpreted as every action belonging to its time or age, that is, it carries its features and expresses it. 
Based on that, it seems that there is no contradiction at all between the two concepts (identity and contemporary) as one of them is concerned with the nature of the subject and the other is concerned with the time of the action, this in terms of formalism and general theory.

And this simplification disappears completely the moment we think about the practical application to the field of contemporary Egyptian visual arts, and this difference comes fundamentally when we realize that both concepts are circulated completely differently from their actual reality, as the concept of identity has been linked to all forms of heritage from successive historical stages, whatever its form. Or its type, and the concept of contemporary is associated with keeping pace with what is happening in the world in terms of styles, materials, methods of expression and means, and the truth is that these practices have completely different names for that, where the identity in this case becomes merely the performance of inspiration or the use of visual and aesthetic data and re-reading History (in the best of hypotheses) or the attempt to ruminate is a civilized achievement in a non-chronological or intellectual context, while contemporary turns into manifestations of the formalism of the tradition, whether in forms or methods.

A and the lengthy introduction to this research confirms that there is no room for achieving an artistic leap beyond the boundaries of what is heritage, fashionable or familiar, except with the occurrence of a civilized development based on an intellectual belief that has its own privacy, which guarantees that it is not similar to the previous methods and forms of artistic expression, as well as with what It is contemporary as it happened in the West during the stages of modern history.

And the reader comes to mind a question that, if that is the case, then what is the position of the Egyptian artistic product over more than a century? And how can we judge it in its general totality from two angles, namely identity and contemporary?

To answer this question, we quickly review how Egyptian artists dealt with concepts of identity and contemporary in their artistic experiences during that period, and we begin with the pioneers of the Egyptian art of photography Mahmoud Saeed, Muhammad Nagy and Ragheb According to the circumstances of his upbringing, Ayyad and Youssef Kamel, who differed in the beginning of each of them and the sources of his artistic formation, all his attachment to art and his professionalism for it.

While both Mahmoud Saeed and Muhammad Naji were able to professionalize art, relying on their free studies and independently visiting international museums, Ragheb Ayad and Youssef Kamel received a regular education at the Higher School of Fine Arts in its first batch when it opened in 1908, and despite that their visions converged. Artisticism in an attempt to reconcile 
several things Mansourin that it will constitute an equivalent to the concepts of identity and contemporary.

All of them used methods and methods of expression drawn from the Western cultural and artistic achievement, whether in formal formulations or aesthetic values, and all of them also tried to benefit from the data of the Egyptian heritage, either by re-using some vocabulary or inspiring constructive solutions, and they also agreed to sing about local issues that celebrate With aspects of Egyptian life (popular, rural, natural, or heritage.

And I see that this combination of history, its data, methods, and then topics presented a different color to images that were not previously known in Egyptian society during the years prior to their existence, but rather that this artistic production foundations for what is known as the Egyptian modern art movement, to which they all belong.

But based on what was previously discussed in this research, were these people and their production able to create an artistic direction and one that establishes a pure Egyptian art?

To answer this question, I will give an example here of what happened in Europe when the Renaissance arts arose when European artists were able to establish forms of art that did not exist before, as well as what happened at the end of the nineteenth century and the beginning of the twentieth century when the movement of development in society produced forms of art They did not exist, and what happened after the Second World War when artists revolted against all existing forms of art, and the philosophy of art in its entirety changed and means of expression, media and methods were developed.

Although that period in Egyptian history was the richest and daring and included many motives, the Egyptian artistic achievement - despite its greatness - did not provide him with real motives or a solid foundation on which to build to be pure art.

The period of the thirties, forties and fifties of the twentieth century witnessed several developments at the level of society, in which calls for independence increased and Egypt participated in World War II, and society interacted with many ideas coming with the soldiers of the countries participating in the war, and on the artistic level many graduated from the art school. The beautiful senior and some of them traveled to study abroad.

Artistic groups were formed, and finally the 1952 revolution came to an end, with the announcement of the nationalization of the Suez Canal and the subsequent aggression against Egypt.

Or on the artistic level, the achievements of an entire generation of artists crystallized. Each group tried to take a path for themselves to produce Egyptian art. Their artistic approaches and intellectual convictions differed, as well as the methods they adopted, and each group of them 
imagined that they are the closest to achieving the Egyptian personality and that it is the most contemporary .

Abdul Hadi Al-Jazzar, Hamid Nada, Muhammad Hamed Owais and many others emerged from them, accompanied by Hussein Baikar and Salah Taher as well.

Also, despite those serious attempts that responded directly to every political and social variable in Egypt, they also could not produce or establish a distinct artistic character or form an influential artistic current, not at the global or local level, and their experiences and attempts remained pure attempts. Individual, and also they did not find in the emerging civilizational project of the ingredients sufficient to create an artistic style or a group of formal vocabulary that could distinguish it from other world arts at that time, and despite the springing spirit that prevailed in Egyptian society in the forties and fifties, which were She is very interested in researching the idea of "Egyptianization" and opening up to the world from the basis of the struggle against the colonial powers and the hegemony of the great powers in the West. However, all of this has not been accompanied by a real development on the ground in the economic, scientific and knowledge aspects of all members of society, which puts Artists face new problems that are solved based on a special value system, most notably societal development in all its features and aspects.

Consequently, the artistic product of these people was limited to the combination of local topics with Western styles. Two basic factors were imposed on this: the first is the strong urgency of the national issue to force itself firmly on all creators, whether supporters or opponents, so the topics became very local in most of them, and the second: the deficit of cultural data The immediate term is not supplying artists with any motivating factors to create a formal current that creates a new plastic mold or special for the emerging Egyptian renaissance.

The situation continued in this way and it also included the subsequent generations of artists who increased their attachment to the Western product as a result of direct contact during scholarships, artistic visits, or friction through participation in international exhibitions, as well as their less attachment to the national project in its general totality as a result of political and social data caused by the fluctuations that occurred. In the sixties or seventies of the twentieth century, whether militarily or politically, such as the shameful defeat in 1967, then the victory of October 1973, and the political agreements and economic measures that followed, which led to the absence of a clear national project that provides artists, creators and thinkers the basic ingredients for a true cultural renaissance, based on a clear intellectual doctrine. Milestones, which led to the absence of the general project, and the tendency of the artists to their individual 
project, trying to balance each from his point of view between his own artistic style, his intellectual convictions, and his view of the world.

With the beginning of the nineties of the twentieth century, and with the policies of the fourth wave - the knowledge revolution - the spatial boundaries faded, and there was no longer that great time difference between the emergence of artistic styles and their emergence at the local level, and many voices announced a rupture with notions of identity, calling for contemporary without full awareness - in My opinion - of course Each term, imagining that the identity recedes in the traditional styles, or the formal attempts to draw inspiration from history, or that modernity lies in keeping pace with what the West is experiencing in terms of innovations of methods and concepts.

However, this wave soon diminished in intensity with the beginning of the new millennium, when artists from the new generations were able to assimilate these new styles and reproduce them again, with multiple reviews of ideas and artistic convictions.

\section{Through all this, I can reach the following:}

First: A researcher cannot deny that the Egyptian artistic experience in the field of visual arts for more than a hundred years has depended on the basic concepts of European art schools, in terms of templates, shapes and principles of design and construction,

Second: It has not adopted any artistic experience of individuals or groups with intellectual references for the emergence of any Western artistic trend, but rather used its apparent principles only, on the formal level, since these forms are closely related to the causes and motives of their appearance with the West, and with civilized projects whose ruling values differ, as an intellectual doctrine. It is radically different from the Egyptian civilization reality in all its stages since the beginning of the twentieth century until now.

Third: The Egyptian artist was able during that period with a brilliant skill to select from formal methods that suit his individual project, and was able to efficiently exploit the formal product of Western arts, and put it into molds containing - without a noticeable defect - on very specific topics, whether they were individual, subjective, or national. A general nation.

Fourth: When a group of innovative artists in the modern Egyptian photography movement wanted to put on their works some local peculiarity (formally), they borrowed pre-made vocabulary from different stages of the Egyptian cultural heritage, whether from its ancient, Coptic or Islamic stage, or even from The formal vocabulary of folk arts, without a real connection to the causes of birth for which these forms were created, and others used them as symbols of some values, virtues or even evils, which were associated with them in their original philosophical structure. 
Fifthly: Perhaps the only project that relied on local visual formulas in their foundations is the project of the Egyptian letters and the accompanying experiences of Arab artists, which is the project based on the idea of using Arabic script letters with their constructive aesthetics, as a visual equivalent to the prevailing Arab culture, in its ancient and contemporary forms And based on the arts of poetry, narration and storytelling, but this team could not deviate from the scope of Western teachings as well, so the Arabic alphabet experiment was based on a background of abstraction principles, in terms of general construction and structural variations. Sixth: The group of innovators and advocates of the necessity of discarding the past, resorting to keeping pace with successive developments in concepts and methods, to desperate attempts to transfer direct or indirect from heritage, without awareness of the nature of the motives, as we have already mentioned, and in most of these experiences ended up reaching the same The result reached by the previous ones, which is to use the formal template or general style in visual treatments and techniques, through topics or stimuli from the local community.

Seventh: The two parties agreed in the end to reach one result, which is the use of formal templates that do not intellectually correspond to the content of artistic works, in terms of their belonging. Society suffers from an extended crisis in its ability to renew its intellectual ideology driving life, so these experiences in their entirety have become a real product. He is an effective representative of the crisis and division of society, and the evidence of his inability to produce motivating ideas that achieve the artist the minimum necessary data to modernize his vocabulary and create his distinctive artistic style, stemming from a real civilized project based on a clear methodology that represents to intellectuals and creators a ruling creed, which pushes him to push for private discovery Necessarily it will fit and algebraically then correspond to its appearance.

Eighth: In spite of all this, the genius of Egyptian artists in all their successive generations emerges in their amazing ability to achieve a very special case of true harmony, between three

\section{factors:}

- Formally imported templates from Western teachings .

- Vocabulary and forms borrowed from heritage sources in their various branches.

- As well as issues that are very specific in terms of their local or subjectivity, which is what makes many Western theorists do not adopt Western academic rules in judging the artistic product of the Egyptians, based on the teachings and characteristics of Western schools, without prior researching the nature of the topics discussed by the works, and reaching their local roots Contemporary or heritage. 


\section{References:}

- $\quad$ Amal Farag SOLIMAN, THE AESTHETIC AND COMMUNICATIVE VALUES

OF ILLUSTRATIONS USED IN INFOGRAPHIC, International Journal of Multidisciplinary Studies in Art and Technology, Vol. 3, No. 1, 2020, pp. 14-23.

- Sherif Massad Muhammad AREF, THE AESTHETIC AND FUNCTIONAL RELATIONSHIP OF THE MINERAL GATHERING IN ISLAMIC ART, International Journal of Multidisciplinary Studies in Art and Technology, Vol. 3, No. 1, 2020, pp. 24-28.

Received: September 5, 2020

Accepted: November 10, 2020 